Author has nothing to disclose with regard to commercial support.

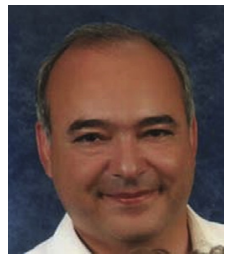

\section{ARCH REPAIR: \\ BRACHIAL ARTERY \\ CANNULATION IS AS \\ EFFECTIVE, BUT LESS \\ INVASIVE AND MORE \\ PRACTICAL}

To the Editor:

We read with great interest the recent comprehensive meta-analysis by Hameed and colleagues, ${ }^{1}$ which provides valuable insight about currently used cerebral protection strategies during aortic arch repair procedures.

As current trends move toward a more physiologically natural cerebral perfusion in terms of flow direction and hypothermia level, antegrade cerebral perfusion through the aortic arch tributaries is gaining popularity. In parallel with this concept, we would like to remind readers of the potential advantages of right brachial artery cannulation compared with the use of the axillary artery for selective unilateral antegrade perfusion of the cerebral tissues. Selective antegrade cerebral perfusion through the right brachial artery for this purpose is as safe and efficient as right axillary artery cannulation, and it is both considerably less invasive and more practical. The cannula insertion and removal are quite fast, easy, and relatively trouble free. Moreover, the cannulation with this technique distinctively does not involve the use of a prosthetic vascular graft, which is an advantage for both complication-minimizing and cost-reducing purposes.

Our group previously reported the efficiency, versatility, and simplicity of this approach in aortic arch repairs, and the details of our technique can be found elsewhere. ${ }^{2}$ Briefly, the patient is placed in a supine position, with the right upper extremity abducted approximately $90^{\circ}$ and rotated externally. Heparin is administrated at the full cardiopulmonary bypass (CPB) dose, and the right brachial artery is cannulated through a $5-\mathrm{cm}$ longitudinal incision high in the bicipital groove near the armpit with a $16 \mathrm{~F}$ to $18 \mathrm{~F}$ venous return catheter without wire reinforcement.

\footnotetext{
The Editor welcomes submissions for possible publication in the Letters to the Editor section that consist of commentary on an article published in the Journal or other relevant issues. Authors should: • Include no more than 500 words of text, three authors, and five references. • Type with double-spacing. • See http://jtcs.ctsnetjournals.org/ misc/ifora.shtml for detailed submission instructions. • Submit the letter electronically via jtcvs.editorialmanager.com. Letters commenting on an article published in the JTCVS will be considered if they are received within 6 weeks of the time the article was published. Authors of the article being commented on will be given an opportunity of offer a timely response ( 2 weeks) to the letter. Authors of letters will be notified that the letter has been received. Unpublished letters cannot be returned.
}

The tip of this cannula may be beveled for easy insertion and to obtain a maximum cross-sectional area. The cannula is then advanced 5 to $7 \mathrm{~cm}$ proximally in the vessel and connected to the CPB circuit as usual. Median sternotomy is performed, and venous cannulation is established through the right atrium.

After the reconstruction of the ascending aorta under cardioplegic arrest with full $\mathrm{CPB}$, the operation may proceed with aortic arch reconstruction. First, the pump flow is decreased to 500 to $700 \mathrm{~mL} \cdot \min ^{-1}(8-10 \mathrm{~mL}$. $\mathrm{kg}^{-1} \cdot \mathrm{min}^{-1}$ ) at $26^{\circ} \mathrm{C}$ to $28^{\circ} \mathrm{C}$ rectal temperature. The 3 brachiocephalic arteries are then individually clamped, and the aortic crossclamp is released. On completion of the arch repair, with the patient in the Trendelenburg position, the clamps on the brachiocephalic vessels are released sequentially, with special attention to evacuating the trapped air. Rewarming then begins as the flow rate is gradually increased to the full preset CPB value. During rewarming, the anastomosis between the ascending aortic and aortic arch grafts is completed. ${ }^{2}$

In our routine use of this variation of selective antegrade cerebral perfusion through the right brachial artery since 1996, our group has demonstrated the safety of this technique in terms of surgical and neurologic outcomes, cerebrovascular protection, preservation of neurocognitive scores, and distal organ protection.

Kerem M. Vural, MD

Department of Cardiovascular Surgery Hacettepe University School of Medicine Ankara, Turkey

\section{References}

1. Hameed I, Rahouma M, Khan FM, Wingo M, Demetres M, Tam DY, et al. Cerebral protection strategies in aortic arch surgery: a network meta-analysis. J Thorac Cardiovasc Surg. February 21, 2019 [Epub ahead of print].

2. Saritas A, Kervan U, Vural KM, Kucuker SA, Yavas S, Birincioglu LC Visceral protection during moderately hypothermic selective antegrade cerebral perfusion through right brachial artery. Eur J Cardiothorac Surg. 2010; 37:669-76.

\section{https://doi.org/10.1016/j.jtcvs.2019.05.042}

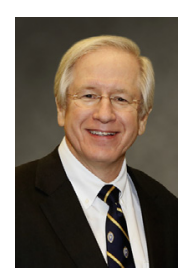

\section{REPLY: KEEP THE ARM IN ARMAMENTARIUM Reply to the Editor:}

Open repair of the transverse aortic arch necessitates interruption of cerebral perfusion, which leaves the brain vulnerable. The brain keeps no energy stores despite being metabolically active even at low temperature and, thus, is in constant need of replenishment. During the past couple of decades, multiple techniques have emerged to provide cerebral protection, and the vast heterogeneity of approaches makes the evaluation of any specific technique 
Author has nothing to disclose with regard to commercial support.

difficult. We are reminded of the herculean efforts of Hameed and colleagues ${ }^{1}$ to assess the optimal strategy to mitigate the prolonged cerebral and distal aortic ischemic times necessitated by aortic arch repair. Among the three approaches studied-antegrade cerebral perfusion (ACP), retrograde cerebral perfusion, and isolated deep hypothermic circulatory arrest-superiority could not be determined by Hameed and colleagues. ${ }^{1}$

In his letter, Vural ${ }^{2}$ asks us to consider yet another factor - the site of arterial cannulation to provide ACP. In the earliest days of aortic arch repair, the innominate artery was used to provide $\mathrm{ACP}^{3}$; however, this was thought to increase the risk of stroke, and the site of cannulation soon shifted to the femoral artery. The femoral artery in turn was found to be an imperfect choice and often heavily atherosclerosed. With time, attention turned to the right axillary artery for the role of primary location for arterial cannulation, which became widespread for many years. ${ }^{4,5}$ Vural $^{2}$ and his colleagues in Turkey ${ }^{6}$ remind us that there is more to the armpit than the right axillary artery and suggest the routine use of the right brachial artery when providing ACP. Potential benefits include ease of cannulation and avoidance of the use of a conduit graft that is commonly applied to the right axillary artery, as well as providing a remote option in case of dissection extending into the brachiocephalic arteries. Although right brachial artery cannulation is a potentially valuable tool in the surgeon's armamentarium, one should proceed with caution in the case of friable tissue (which is common in patients with connective tissue disorder) or small brachial arteries.

Joseph S. Coselli, MD

Division of Cardiothoracic Surgery Michael E. DeBakey Department of Surgery Baylor College of Medicine Houston, Tex Department of Cardiovascular Surgery Texas Heart Institute

Houston, Tex CHI St Luke's Health-Baylor St Luke's Medical Center Houston, Tex
2. Vural KM. Arch repair: brachial artery cannulation is as effective, but less invasive and more practical. J Thorac Cardiovasc Surg. 2019;158:e165.

3. DeBakey ME, Crawford ES, Cooley DA, Morris GC Jr. Successful resection of fusiform aneurysm of aortic arch with replacement by homograft. Surg Gynecol Obstet. 1957; 105:657-64.

4. De Paulis R, Czerny M, Weltert L, Bavaria J, Borger MA, Carrel TP, et al; EACTS Vascular Domain Group. Current trends in cannulation and neuroprotection during surgery of the aortic arch in Europe. Eur J Cardiothorac Surg. 2015;47:917-23.

5. Sabik JF, Lytle BW, McCarthy PM, Cosgrove DM. Axillary artery: an alternative site of arterial cannulation for patients with extensive aortic and peripheral vascular disease. J Thorac Cardiovasc Surg. 1995;109:885-90; discussion 90-1.

6. Saritas A, Kervan U, Vural KM, Kucuker SA, Yavas S, Birincioglu LC Visceral protection during moderately hypothermic selective antegrade cerebral perfusion through right brachial artery. Eur J Cardiothorac Surg. 2010; 37:669-76

https://doi.org/10.1016/j.jtcvs.2019.05.036

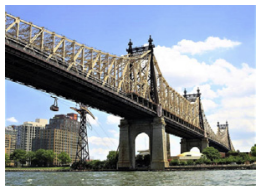

REPLY: PERFUSION: IS HIGHER BETTER?

Reply to the Editor:

We thank Vural $^{1}$ for his letter regarding our recently published network meta-analysis ${ }^{2}$ on cerebral protection strategies in aortic arch surgery. We read with great interest his description of right brachial artery selective antegrade cerebral perfusion and its possible benefits. ${ }^{3}$ Our network meta-analysis ${ }^{2}$ lends further evidence to the benefits of more physiologically natural cerebral protection techniques during aortic arch surgery. We found both antegrade and retrograde cerebral perfusion techniques to be associated with better postoperative outcomes than deep hypothermic circulatory arrest. It is therefore an interesting prospect to reexamine current variations of these cerebral perfusion strategies to standardize the choice of perfusion site and possibly to define patients that could benefit from the individual strategies. Although the potential advantages of the brachial selective cerebral perfusion approach relative to axillary cannulation are interesting, perfusion site remains an important issue in aortic surgery. Larger studies and trials comparing different approaches are clearly needed.

Irbaz Hameed, $M D$

Mario Gaudino, $M D$

Department of Cardiothoracic Surgery

Weill Cornell Medicine

New York, $N Y$

\section{References}

1. Vural K. Arch repair: brachial artery cannulation is as effective, but less invasive and more practical. J Thorac Cardiovasc Surg. 2019;158:e165. 